\title{
Effects of halolactones with strong feeding-deterrent activity on the growth and development of larvae of the lesser mealworm, Alphitobius diaperinus (Coleoptera: Tenebrionidae)
}

\author{
Maryla Szczepanik $^{1}$ - Anna Gliszczyńska ${ }^{2}$ Maksymilian Hnatejko ${ }^{1} \cdot$ \\ Beata Zawitowska ${ }^{1}$
}

Received: 10 June 2015 / Accepted: 23 February 2016 / Published online: 2 May 2016

(C) The Author(s) 2016. This article is published with open access at Springerlink.com

\begin{abstract}
The effects of dietary applied of $\beta$-damascone and its synthetic derivatives $\gamma$ - and $\delta$-halolactones, which show strong antifeedant activity, on the growth and development of larvae of the lesser mealworm, Alphitobius diaperinus Panzer (Coleoptera: Tenebrionidae), were studied. Bioassays were performed in a dose-dependent manner. In the bioassays, oat flakes treated with 1.0, 0.5 , and $0.1 \%$ $(\mathrm{w} / \mathrm{v})$ acetone solutions of the tested compound or acetone alone as control were served as food. The experiments were conducted using 2-week-old larvae with an average body weight of 4.35-4.88 mg. High correlations between antifeedant activity and larvicidal and growth-inhibitory effects were observed. Larvae reared on diets containing the compounds (at a concentration of $1 \%$ ) with high deterrent activity were characterized by a prolonged period of development, lower body weight gain, and strong tendency for cannibalism as a result of starvation. The control larvae ended their development after 24 days with a mean body weight of $22.9 \mathrm{mg}$. At the same developmental time, the mean body weights of larvae treated with the $\delta$-halolactones $\gamma$-chloro- and $\gamma$-bromo- $\delta$-lactone were only $60.3 \%$ and $43.2 \%$ of that of the control larvae. The larval periods for larvae on the diets containing $\gamma$-chloro- and $\gamma$-bromo- $\delta$-lactone were 33 and 41 days, respectively. The larval developmental time and body weight gain were not significantly influenced by lower doses of the compounds,
\end{abstract}

Maryla Szczepanik

mszczep@umk.pl

1 Faculty of Biology and Environment Protection, Nicolaus Copernicus University, Lwowska 1, 87-100 Toruń, Poland

2 Department of Chemistry, Wroclaw University of Environmental and Life Sciences, Norwida 25, 50-375 Wrocław, Poland with the exception of $\gamma$-bromo- $\delta$-lactone. This compound, when applied at a concentration of $0.5 \%$, significantly prolonged larval development as compared to the control larvae, and caused high mortality of larvae and pupae. The adult emergence percentage was $37.51 \%$ when this treatment was applied, as compared to $90.0 \%$ in the control. Thus, $\beta$-damascone derivatives with a lactone ring exhibit both dose-dependent behavioral effects and post-ingestion toxicity against $A$. diaperinus larvae, and may have the potential to control this pest.

Keywords Damascone · Antifeedants · Halolactones · Biopesticides $\cdot$ Alphitobius diaperinus

\section{Introduction}

Numerous problems associated with the use of chemical insecticides have led researchers to look for natural agents that can be directed against insect pests. Bioactive compounds from plants are considered an ecologically safe source of environmentally friendly insecticides, and they help to reduce synthetic insecticide usage (Miresmailli and Isman 2014). These compounds with various chemical structures are accumulated in plant tissues and act as a defense system against phytopathogens and herbivores due to their antifungal, antiviral, antibacterial, and insecticidal properties (Bassolé and Juliani 2010; Ćosić et al. 2010; Pattnaik et al. 1997). Some of the defensive compounds may affect insect growth or physiology, and many are toxic, but their primary function may be to modify behavior (Bernays and Graham 1988; Rodriguez-Saona and Trumble 1999). Many of them are characterized by repellent, antioviposition, or antifeedant activities against both agricultural pests and insects that are important from a medical or 
veterinary perspective (Baskar et al. 2009; Koul et al. 2008; Regnault-Roger et al. 2012). Secondary plant metabolites that exhibit a high level of antifeedant activity play a more important role in insect food selection than feeding attractants or stimulants (Nawrot and Harmatha 2012). Numerous studies of natural or synthetic antifeedants show a correlation between chemical structure and antifeedant activity. The characteristic feature of antifeedants is their high specificity; their deterrent effect depends on the insect species considered (Schoonhoven 1982).

However, compounds of natural origin-while possessing many useful characteristics - can only be used to a limited extent, mainly because of their presence at only low levels in plants and the expense involved in obtaining these active ingredients. Knowledge of the structures of these compounds may facilitate the development of synthetic analogs or derivatives of them. The chemical transformation of natural compounds by incorporating the elements responsible for antifeedant activity into their structures can provide antifeedants that show rapid biodegradation and low toxicity in mammals. Components of essential oils, especially terpenes, can be used as precursors for active feeding deterrents (Dancewicz et al. 2008; Lochyński et al. 2002; Popławski et al. 2000; Szczepanik et al. 2014).

$\beta$-Damascone, also known as a rose ketone, was isolated from Bulgarian rose oil (Demole et al. 1970). It is mainly used in the perfume industry due to its pleasant smell, but it is also known for its insecticidal activity. According to Kaufman et al. (2011), $\beta$-damascone could be used against insecticide-resistant strains of the housefly, Musca domestica L. (Diptera: Muscidae), and other biting flies of medical and veterinary importance. Derivatives of it with a lactone ring that were synthesized in our lab showed high antifeedant activity against the lesser mealworm, Alphitobius diaperinus Panzer (Gliszczyńska et al. 2014). Out of the 11 compounds evaluated, three of them were particularly active against larvae of this pest: $\gamma$ - and $\delta$-chlorolactones as well as a $\delta$-bromolactone. As described in the literature, antifeedant activity is also often associated with other biological effects against insects, such as larval growth inhibition, chronic toxicity, antioviposition, and reduced fertility (Akhtar and Isman 2004; Jeyasankar et al. 2010, 2014; Pavela et al. 2008). Studying nutritional indices such as relative consumption and growth rates after the ingestion of potential antifeedants can help to determine whether a chemical compound exhibits not only antifeedant activity but also toxicity following ingestion (Zapata et al. 2009).

The work described in the present paper is a continuation of our previous studies, and focuses on the effects of a few selected halolactones with strong deterrent activities that were obtained from $\beta$-damascone on the development of A. diaperinus. Our aim was to investigate if the antifeedant effects of these halolactones are long-lived and influence the larval growth, development, pupation rate, pupal and adult masses, adult emergence rate, and survival of the lesser mealworm. This insect is one of the most important and widespread pests in commercial poultry production around the world. It is capable of transmitting a large number of poultry diseases and parasites. All stages of the pest can act either as reservoirs or external carriers of serious poultry diseases, including Newcastle and Marek's diseases, and can also act as intermediate hosts for tapeworms and protozoans (Lambkin 2001). The beetle is also known to be a pest of animal feeds, especially those kept in neglected storage rooms. This pest is usually controlled with chemical insecticides such as insect growth regulators and pyrethroids. Continuous usage of these insecticides leads to the selection of the resistant pest population (Chernaki-Leffer et al. 2011). Thus, many studies have been performed to identify natural substances or derivatives of them that can be used as insecticides with low environmental risk (Koul et al. 2008; Regnault-Roger et al. 2012). In this work, the insecticidal activities of derivatives with completely new structures were compared with the activity of the starting compound $\beta$-damascone.

\section{Materials and methods}

\section{Chemicals}

The structures of the compounds applied in the bioassays reported here are illustrated in Fig. 1. In this group is a natural ketone, $\beta$-damascone (1), as well as three halolactones synthesized from it: 7a-(1-chlorobutyl)-3a,7,7-trimethylhexahydrobenzofuran-2-one (2); 7a-chloro-3a,7,7trimethyl-8-propyloctahydroizochromen-2-one (3), and

Fig. 1 Chemical structures of the compounds (1-4) studied in this work

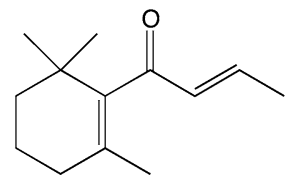

1

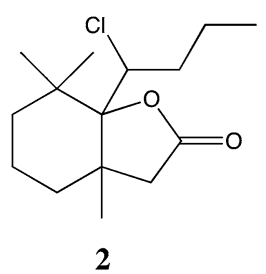

2

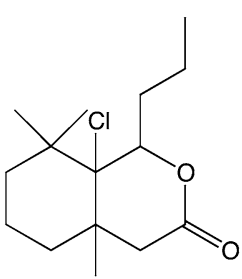

3

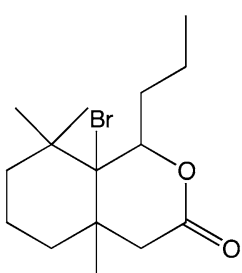

4 
7a-bromo-3a,7,7-trimethyl-8-propyloctahydroisochromen3-one (4) (Gliszczyńska et al. 2014). $\beta$-Damascone (1) was purchased from Sigma-Aldrich. The first step in the synthesis was the reduction of the double bond in the side chain of $\beta$-damascone (1) with $\mathrm{LiAlH}_{4}$ to a ketone, leading to dihydro- $\beta$-damascone, which was subsequently transformed into the corresponding allylic alcohol: dihydro- $\beta$ damascol. The Claisen-Johnson rearrangement (orthoacetate modification) of the alcohol was the key step in the synthesis. A $\gamma, \delta$-unsaturated ethyl ester was the product of this rearrangement, ethyl 2-(2-butylidene-1,3,3-trimethylcyclohexyl) acetate, which was then hydrolyzed $(\mathrm{KOH}$, $\mathrm{EtOH})$ to 2-(2-butylidene-1,3,3-trimethyl-cyclohexyl) acetic acid. This was converted into a $\delta$-halo- $\gamma$-lactone, $7 a$-(1-chlorobutyl)-3a,7,7-trimethylhexahydrobenzofuran-2-one (2) (18\% yield), and two $\gamma$-halo- $\delta$-lactones, 7a-chloro-3a,7,7-trimethyl-8-propyloctahydroizochromen2-one (3) (17\% yield) and 7a-bromo-3a,7,7-trimethyl8-propyl-octahydroisochromen-3-one (4) (27\% yield), in bromo- and chlorolactonization processes performed under basic conditions (NBS/NCS, THF). The purities of compounds 1-4 were $>99 \%$ according to GC analysis.

\section{Bioassays}

\section{Insect culture}

Larvae of the lesser mealworm from a laboratory colony were used in these studies. The insects were originally collected from poultry house litter in a commercial chicken farm near Torun $\left(53^{\circ} 01^{\prime} \mathrm{N}, 18^{\circ} 37^{\prime} \mathrm{E}\right.$, Poland). In the laboratory, the insects were kept in glass containers on a basic diet consisting of 1 part oat flakes, 1 part wheat bran, 0.01 parts brewers' yeast, and apple halves to maintain moisture levels at ca. $60 \pm 5 \%$ r.h. The colony was kept in a rearing chamber at $+29^{\circ} \mathrm{C}$ in the dark.

\section{Feeding-deterrent activity}

The feeding-deterrent activities of the compounds studied here against larvae and adults of $A$. diaperinus were determined using the standard method of choice and no-choice tests, as described previously (Gliszczyńska et al. 2014). The relative deterrence coefficient $R$ was calculated using the following formula:

$R=\frac{(C-E)}{(C+E)} \times 100$,

where $C$ and $E$ are the weights of the control and treated foods consumed by the insects in the choice test, respectively. The absolute deterrence coefficient $A$ was calculated using the same formula, while $C$ and $E$ were obtained from the no-choice test.

\section{Chronic larval growth, development, and survival bioassays}

The effects of $\beta$-damascone and its derivatives on larval growth and development were studied by incorporating them as acetone solutions into the diet. The studies described here were performed in a dose-dependent manner. 1.0, 0.5, and $0.1 \%(\mathrm{w} / \mathrm{v})$ acetone solutions of the compounds were applied in bioassays. One gram of oat flakes was treated with $1 \mathrm{~mL}$ of the tested solution or acetone alone (the control) using a micropipette. This corresponded to a dose of 10.0, 5.0 , or $1.0 \mathrm{mg}$ of each compound per gram of diet, respectively. After solvent evaporation, oat flakes were placed in plastic containers with a capacity of $100 \mathrm{~mL}$ together with the moist cotton ball to keep the relative humidity below $55 \%$. Ten two-week-old larvae with an average body weight of 4.35-4.88 mg were placed in each container, fed ad libitum, and kept in an incubator under the same conditions as used to maintain the colony. During the developmental period, larval body weight gain and survivability were recorded at 6-day intervals. The surviving larvae received the treated food until the pupal stage. When the larva had completed their development, the resulting pupae were transferred to small plastic containers with a piece of wet cotton wool. The larval developmental times were recorded and the pupae (approximately $24 \mathrm{~h}$ old) were weighed. Upon successful adult emergence, before they began to feed, the body weights of the insects were also recorded. The pupation and adult emergence percentages were calculated from the formula: \% pupation or adult emergence $=100 \times($ total number of pupae or adults formed)/(total number of larvae released) (Singh et al. 2010). The mortality of the pupae was also recorded. Each experiment was replicated three times, with 10 larvae per replicate.

\section{Statistical analysis}

The data were statistically analyzed by means of one-way analysis of variance (ANOVA) followed by Tukey's test $(\alpha=0.05)$ using the Paleontological Statistics (PAST) software (Hammer et al. 2001).

\section{Results and discussion}

The compounds tested in these studies differed in their feeding-deterrent activities. The antifeedant properties of the compounds were assessed on the basis of their deterrence coefficients. Generally, the higher the value of this 
Table 1 Feeding-deterrent activities of the compounds studied in the choice and no-choice tests against $A$. diaperinus larvae

\begin{tabular}{lllll}
\hline Dose (\%) & Compound $^{\mathrm{a}}$ & \multicolumn{2}{l}{ Deterrence coefficients (mean \pm SE) } & \multicolumn{2}{l}{$\begin{array}{l}\text { Consumption } \\
(\%)^{\mathrm{b}}\end{array}$} \\
\cline { 3 - 5 } & & $R$ & $A$ & \\
\hline $1.0^{\mathrm{c}}$ & $\mathbf{1}$ & $55.59 \pm 3.41 \mathrm{abc}$ & $30.70 \pm 15.94 \mathrm{ab}$ & $59.26 \pm 17.31 \mathrm{bcd}$ \\
& $\mathbf{2}$ & $97.77 \pm 0.53 \mathrm{~d}$ & $67.04 \pm 4.36 \mathrm{bc}$ & $21.44 \pm 8.26 \mathrm{ab}$ \\
& $\mathbf{3}$ & $98.29 \pm 2.96 \mathrm{~d}$ & $85.71 \pm 5.30 \mathrm{c}$ & $7.88 \pm 2.64 \mathrm{a}$ \\
& $\mathbf{4}$ & $80.19 \pm 1.17 \mathrm{c}$ & $82.45 \pm 11.50 \mathrm{c}$ & $9.69 \pm 1.67 \mathrm{a}$ \\
$0.5^{\mathrm{c}}$ & $\mathbf{1}$ & $30.09 \pm 1.66 \mathrm{a}$ & $12.75 \pm 0.18 \mathrm{a}$ & $88.81 \pm 0.44 \mathrm{~d}$ \\
& $\mathbf{2}$ & $84.22 \pm 6.03 \mathrm{c}$ & $29.99 \pm 6.83 \mathrm{ab}$ & $58.28 \pm 9.02 \mathrm{bcd}$ \\
& $\mathbf{3}$ & $65.62 \pm 11.96 \mathrm{bc}$ & $48.25 \pm 9.42 \mathrm{abc}$ & $36.59 \pm 9.71 \mathrm{abc}$ \\
& $\mathbf{4}$ & $84.61 \pm 4.97 \mathrm{c}$ & $29.78 \pm 14.52 \mathrm{ab}$ & $59.25 \pm 15.40 \mathrm{bcd}$ \\
0.1 & $\mathbf{3}$ & $32.71 \pm 13.05 \mathrm{ab}$ & $11.21 \pm 4.97 \mathrm{a}$ & $80.87 \pm 7.71 \mathrm{c}$ \\
& $\mathbf{4}$ & $58.32 \pm 15.23 \mathrm{bc}$ & $8.18 \pm 1.52 \mathrm{a}$ & $84.98 \pm 1.52 \mathrm{~d}$ \\
& $F$ & 12.35 & 8.89 & 10.73 \\
& $d f$ & 9 & 9 & 9 \\
& $p$ & $<0.001$ & $<0.001$ & $<0.001$ \\
\hline
\end{tabular}

$R$ relative coefficient (choice test), $A$ absolute coefficient (no-choice test)

Means followed by the same letters within each column are not significantly different (one-way ANOVA and Tukey's test, $p<0.05$ )

${ }^{\text {a }}$ For structures of the compounds labeled by number in this column, see Fig. 1

b Data are expressed as percentages of the consumption of the control in the no-choice test

${ }^{c}$ From Gliszczyńska et al. (2014) index, the lower the rate of feeding (Table 1). The starting substrate, $\beta$-damascone, was the weakest antifeedant of the compounds tested. In the no-choice test, the consumption of food treated with 1 and $0.5 \%$ concentrations of this compound was decreased by about 40 and $11 \%$, respectively, as compared with the control food. Chemical modification of the $\beta$-damascone structure leads to increased antifeedant activity of the resulting derivatives. During experiments, we observed structure- and dose-dependent relationships. The halolactones with a $\delta$-lactone moiety ( 3 and 4 ) were the most active compounds. These differences in activity among the compounds were particularly visible in the nochoice tests where feeding was strongly suppressed. The consumption of food treated with the maximum dose of $\delta$-halolactones was more than $7(3)$ or $6(4)$ times lower than the consumption of food treated with $\beta$-damascone (1). The larval feeding rate was reduced threefold by $\delta$-chloro- $\gamma$ lactone (2) in comparison to $\beta$-damascone, while the activity of $\delta$-bromo- $\gamma$-lactone was found to be similar to that of $\beta$-damascone, so this compound was not considered in the present studies (Gliszczyńska et al. 2014). Cutting the dosage of halolactones by half led to a decrease in deterrent activity. When $0.5 \%$ solutions of the $\delta$-halolactones were used, consumption increased more than sixfold (when $\mathbf{4}$ was used) and about fivefold (when $\mathbf{3}$ was used) in relation to the consumption observed with $1 \%$ solutions. The lowest dose $(0.1 \%)$ of each compound was almost completely ineffective as an antifeedant (Table 1).
The antifeedant efficiencies of a significant number of chemical compounds depend on the dose and exposure time. After a long exposure period, some of these compounds lose their antifeedant properties due to the development of resistance in the insects that consume the contaminated food, degradation of the compounds, or habituation (Pavela 2011; Rodriguez-Saona and Trumble 1999). None of these phenomena were observed for the most potent antifeedants (i.e., $\delta$-halolactones at a concentration of $1 \%$ ) studied in this work; the compounds showed permanent antifeedant activity across the whole test period. The antifeedant effect was rather short-lived after the application of $\delta$-chloro- $\gamma$-lactone (2). While the deterrence coefficients determined in three-day assays (Gliszczyńska et al. 2014) indicated that $\delta$-chloro- $\gamma$-lactone possesses high activity, larval feeding rates started to increase when it was used over a long period. Likely, persin presented high deterrence against larvae of Spodoptera exigua Hübner (Lepidoptera: Noctuidae) during the first $72 \mathrm{~h}$, but after that the deterrence declined (Rodriguez-Saona et al. 1997). Therefore, studies of feeding deterrents should have a broader scope than just the determination of the deterrence coefficients.

One of the consequences of feeding inhibition is a low body-weight gain. The larval body weights of larvae treated with the maximum doses of compounds $\mathbf{3}$ and $\mathbf{4}$ were considerably lower than those of the control larvae. After 12 days of culture, the body weights of the larvae treated with $\delta$-halolactones had increased approximately 1.5 -fold, 
Table 2 Growth of $A$. diaperinus larvae reared on a diet treated with different concentrations of $\beta$-damascone and halolactones

\begin{tabular}{|c|c|c|c|c|c|c|c|}
\hline \multirow[t]{2}{*}{ Dose $(\%)$} & \multirow[t]{2}{*}{ Compound $^{\mathrm{a}}$} & \multicolumn{6}{|c|}{ Body weights $(\mathrm{mg}) \pm \mathrm{SE}^{\mathrm{b}}$ on particular post-treatment days } \\
\hline & & 0 & 6 & 12 & 18 & 24 & $\mathrm{BWRC}^{\mathrm{c}}$ \\
\hline & Control & $4.44 \pm 0.09 a$ & $10.60 \pm 0.78 \mathrm{ab}$ & $19.82 \pm 0.22 \mathrm{a}$ & $22.41 \pm 1.18 \mathrm{a}$ & $22.9 \pm 0.00 \mathrm{a}$ & - \\
\hline \multirow[t]{4}{*}{1.0} & 1 & $4.88 \pm 0.28 \mathrm{a}$ & $10.43 \pm 0.90 \mathrm{ab}$ & $15.93 \pm 1.47 \mathrm{bcd}$ & $20.85 \pm 1.78 \mathrm{abc}$ & $21.80 \pm 0.00 \mathrm{ab}$ & 95.20 \\
\hline & 2 & $4.41 \pm 0.02 \mathrm{a}$ & $8.85 \pm 0.31 b$ & $13.54 \pm 0.09 \mathrm{~cd}$ & $16.52 \pm 0.67 \mathrm{~cd}$ & $19.75 \pm 1.39 \mathrm{ab}$ & 86.20 \\
\hline & 3 & $4.53 \pm 0.14 \mathrm{a}$ & $4.62 \pm 0.17 \mathrm{c}$ & $7.03 \pm 0.30 \mathrm{e}$ & $9.85 \pm 1.08 \mathrm{e}$ & $13.81 \pm 1.70 \mathrm{c}$ & 60.30 \\
\hline & 4 & $4.35 \pm 0.10 \mathrm{a}$ & $4.47 \pm 0.57 \mathrm{~d}$ & $6.11 \pm 0.70 \mathrm{e}$ & $8.40 \pm 1.48 \mathrm{e}$ & $9.90 \pm 2.29 \mathrm{~d}$ & 43.20 \\
\hline \multirow[t]{4}{*}{0.5} & 1 & $4.41 \pm 0.05 \mathrm{a}$ & $9.16 \pm 0.18 b$ & $17.21 \pm 0.95 b c$ & $20.65 \pm 1.80 \mathrm{abc}$ & $21.28 \pm 2.06 \mathrm{ab}$ & 92.90 \\
\hline & 2 & $4.54 \pm 0.05 \mathrm{a}$ & $11.19 \pm 0.53 a$ & $17.56 \pm 0.72 \mathrm{ab}$ & $21.40 \pm 0.31 \mathrm{ab}$ & $22.21 \pm 1.05 \mathrm{a}$ & 96.99 \\
\hline & 3 & $4.44 \pm 0.07 a$ & $8.40 \pm 0.37 c$ & $13.05 \pm 0.71 d$ & $16.65 \pm 0.85 \mathrm{bcd}$ & $17.00 \pm 0.69 b c$ & 74.24 \\
\hline & 4 & $4.38 \pm 0.03 a$ & $5.49 \pm 0.14 c$ & $9.09 \pm 0.79 \mathrm{e}$ & $12.46 \pm 0.81 \mathrm{de}$ & $14.66 \pm 0.45 c$ & 64.03 \\
\hline \multirow[t]{5}{*}{0.1} & 3 & $4.37 \pm 0.11 \mathrm{a}$ & $9.45 \pm 0.66 a b$ & $16.98 \pm 0.53 \mathrm{abc}$ & $19.09 \pm 0.77 \mathrm{abc}$ & $21.36 \pm 0.59 a b$ & 93.27 \\
\hline & 4 & $4.59 \pm 0.09 a$ & $8.83 \pm 0.82 b$ & $15.97 \pm 0.57 \mathrm{bcd}$ & $18.94 \pm 1.06 \mathrm{abc}$ & $19.83 \pm 0.68 \mathrm{ab}$ & 86.58 \\
\hline & $F$ & - & 24.95 & 37.84 & 23.65 & 16.37 & \\
\hline & $d f$ & - & 10 & 10 & 10 & 10 & \\
\hline & $p$ & - & $<0.001$ & $<0.001$ & $<0.001$ & $<0.001$ & \\
\hline
\end{tabular}

Means followed by the same letters within a column are not significantly different (one-way ANOVA and Tukey's test, $p<0.05$ )

${ }^{\text {a }}$ For structures of the compounds labeled by number in this column, see Fig. 1

${ }^{\mathrm{b}}$ Each value is the mean of three replicates, each set up with ten larvae $(n=30)$

c Body weight relative to control (\%)

while the increase in body weight for the control larvae was about 4.5 times. Larval growth in the presence of $\beta$-damascone was only slightly slower (3.6-fold increase) than that of the control.

In the control trials, larvae ended their development after 24 days with a mean body weight of $22.9 \mathrm{mg}$. At the same time, the mean body weights of larvae treated with $\delta$-halolactones were only $43.2 \%(4)$ and $60.3 \%(3)$ of the mean body weight of the control larvae (Table 2). The smallest body weight gain of the larvae was observed after the application of $\gamma$-bromo- $\delta$-lactone (4). Admittedly, this compound showed slightly weaker antifeedant activity in the no-choice test than $\gamma$-chloro- $\delta$-lactone (3) did, but this difference was not significant (Table 1). Thus, these compounds showed the strongest inhibitory activities towards both feeding and larval growth when administered at their maximum doses. However, their ability to reduce the pest population through their antifeedant action is crucial.

In our studies, larval growth was also affected by the application of a lower dose $(0.5 \%)$ of $\delta$-halolactones 3 and 4, despite a decrease in antifeedant activity in the no-choice test. In the choice test, the activities of these compounds remained high as a result of their effects on the chemoreceptors. This is typical of many antifeedants. Usually, the mean values of the relative coefficients are higher than those of the absolute coefficients. The conclusions drawn from the choice test must be confirmed by comparing the results obtained in the choice test with those obtained in the no-choice test. In this test, larvae only had access to the treated food, so only strong stimulation of their chemoreceptors would stop them feeding. The no-choice situation is often more representative of an agricultural system (Koul 2004; Nawrot and Harmatha 2012). Our previous studies showed that larvae of the lesser mealworm are more sensitive to antifeedants in the choice test than in the no-choice situation (Szczepanik et al. 2008, 2014). Only in the case of a very strong feeding deterrent are both deterrence coefficients very high, and just such a situation was observed after applying the $\delta$-halolactones $\mathbf{3}$ and $\mathbf{4}$ at a concentration of $1 \%$ (Table 1).

On the other hand, a concentration of $0.5 \% \delta$-chloro- $\gamma$ lactone (2) had no effect on the growth of larvae. The deterrence coefficients of lactones $\mathbf{2}$ and $\mathbf{4}$ were almost identical in both tests, but these lactones had different impacts on larval growth. This may suggest that the antifeedant activity of compound $\mathbf{2}$ is relatively short-acting, and/or that compounds $\mathbf{3}$ and $\mathbf{4}$ have toxic effects following ingestion. A smaller reduction in the growth rate was observed after the application of lactone $\mathbf{3}$, which showed higher deterrent activity in the no-choice test. The differences in these parameters from those of lactone $\mathbf{4}$ were not significant, but they were significant in comparison with those of the control. The growth of larvae that consumed $\delta$-halolactones at a concentration of $0.1 \%$ was similar to that of the control (Table 2). 
Strong antifeedant activities of natural compounds or their derivatives along with a reduction in larval growth are relatively commonly observations. Limonoids, phragmalin, and mexicanolide obtained from Khaya senegalensis (Desr.) A. Juss (Meliaceae) exhibited strong antifeedant activity against the cotton leafworm, Spodoptera littoralis Boisduval (Lepidoptera: Noctuidae), and inhibited larval growth (El-Aswad et al. 2003). Extract of the seeds of Melia volkensii Gürke (Meliaceae) appears to act as a strong antifeedant and an effective growth inhibitor of cabbage looper, Trichoplusia ni Hübner (Lepidoptera: Noctuidae), and the armyworm, Pseudaletia unipuncta Haworth (Lepidoptera: Noctuidae) (Akhtar and Isman 2004). Likewise, two avocadofurans with antifeedant activity against the generalist insect herbivore $S$. exigua were found to reduce the larval growth of late-stadium larvae, and significantly extended their development times, even at sublethal concentrations (Rodriguez-Saona and Trumble 1999). Chronic inhibition of larval growth after the application of feeding deterrents may be due to not only an antifeedant effect but also a behavioral deterrence combined with a post-ingestive toxic effect (Isman et al. 1989; Pavela et al. 2008; Stefanazi et al. 2011; Zapata et al. 2009). When some sesquiterpene lactones were incorporated into the diet of Tenebrio molitor L. (Coleoptera: Tenebrionidae), its conversion of ingested food in insect biomass decreased (Rosiński et al. 1988).

The compounds studied here do not appear to be toxic because we did not observe any dead larvae shortly after applying the compounds to the food. The strong reduction in the pupation rate after applying $\delta$-halolactones $\mathbf{3}$ and $\mathbf{4}$ at $1 \%$ concentration was due to a high level of cannibalism among the larvae, triggered by the effect of starvation. When there were high deterrence coefficients, it was difficult to determine whether there was a post-ingestive effect because the larvae barely fed. When they are not willing to accept the treated food made available to them, the starving larvae sought out other sources of food. This phenomenon is often observed among insects reared under unfavorable conditions (lack of food, water, high density, etc.) (Richardson et al. 2010). After the application of antifeedants, the more sensitive and weaker larvae were eaten by the stronger ones before pupation. This alternative food contributed to the growth and survival of a few larvae and their formation of pupae. A. diaperinus is an omnivorous insect; it can eat both plant and animal foods. The level of cannibalism observed was dose-dependent. In the control trials, this phenomenon was observed sporadically, as it was after applying the lower doses of the compounds, especially a concentration of $0.1 \%$. In trials where the concentration of the $\delta$-halolactone was $0.5 \%$, the rate of cannibalism was $<15 \%(10-13.3 \%)$. According to Bouayad et al. (2013), cannibalistic behavior was observed in insects exposed to plant extracts with antifeedant activity. For example, extracts of Centaurium erythraea Rafn (Gentianaceae) and Rosmarinus officinalis L. (Lamiaceae) induced marked cannibalism (20-25\%) between larvae of Plodia interpunctella Hübner (Lepidoptera: Pyralidae), similar to that observed in starved larvae (30\%). Furthermore, Rharrabe et al. (2007) reported that the presence of harmaline, a $\beta$-carboline alkaloid that is a secondary metabolic compound in plants, in the diet of larvae of $P$. interpunctella caused the appearance of cannibalistic behavior.

Larvae with low body weights were characterized by a significantly prolonged period of development in comparison with the control ones (Table 3). The duration of the larval period was correlated with the antifeedant activity of the tested compound-the starvation induced by the compound resulted in growth inhibition. The highest dose of $\delta$-halolactone, which was correlated with strong antifeedant activity, led to the greatest prolongation of larval development. The larval periods for larvae fed on diets containing $\gamma$-chloro- and $\gamma$-bromo- $\delta$-lactone were 33 and 41 days, respectively, while that for the control group was only 21 days (Table 3). Prolonged development caused by starvation was also seen in $T . n i$, for which there was a direct correlation between larval duration and the level of starvation (Tignor and Eaton 1986). Larval developmental time was not significantly influenced by compound $\mathbf{2}$, which exhibited relatively low antifeedant activity. After treatment with a moderate dose $(0.5 \%)$, larval duration was only increased significantly by $\gamma$-bromo- $\delta$-lactone (4); treatment with the other compounds at a moderate dose led to similar larval durations to that seen for the control (Table 3).

Pupal and adult weights were influenced by treatment with any of the tested compounds, but the pupal weight was reduced to the greatest degree by the $\delta$-lactones, especially $\gamma$-bromo- $\delta$-lactone (4). This compound was effective at both high and moderate doses (1.0 and $0.5 \%)$. The weights of the pupae that received either of these treatments were the lowest. Poor antifeedants had a relatively weak reductive effect on the body weights of pupae and adults as well as pupation percentages in comparison with those of the control (Table 3). Thus, the quantity and quality of the available food are key influences on the growth, development, and reproduction of insects (Liu et al. 2013). Cereal flours, especially rice flour, reduced the growth of larvae, pupae, and adults of A. diaperinus, lowered pupation and adult emergence, and significantly lengthened the developmental time (Hosen et al. 2004).

In our studies, adult emergence rates varied and were lower than the pupation rates, even in the controls, but the number of adults that emerged was strongly affected in three treatments: those with $\beta$-damascone and lactone 2 at $1 \%$ concentration and that with lactone 4 at $0.5 \%$ concentration. Some of the adults that emerged from the 
Table 3 Effects of different concentrations of $\beta$-damascone and halolactones on the development of A. diaperinus larvae

\begin{tabular}{|c|c|c|c|c|c|c|}
\hline Dose $(\%)$ & Compound $^{\mathrm{a}}$ & $\begin{array}{l}\text { Larval duration } \\
\text { (days } \pm \mathrm{SE})\end{array}$ & $\begin{array}{l}\text { Pupation } \\
(\% \pm \mathrm{SE})\end{array}$ & $\begin{array}{l}\text { Pupal weight } \\
(\mathrm{mg} \pm \mathrm{SE})\end{array}$ & $\begin{array}{l}\text { Adult emergence } \\
(\% \pm \mathrm{SE})\end{array}$ & $\begin{array}{l}\text { Adult weight } \\
(\mathrm{mg} \pm \mathrm{SE})\end{array}$ \\
\hline & Control & $21.0 \pm 1.73 \mathrm{a}$ & $96.7 \pm 3.33 \mathrm{a}$ & $19.17 \pm 1.06 \mathrm{a}$ & $90.0 \pm 5.77 \mathrm{a}$ & $14.94 \pm 0.55 \mathrm{a}$ \\
\hline \multirow[t]{4}{*}{1.0} & 1 & $25.0 \pm 2.0 \mathrm{ab}$ & $70.0 \pm 5.77 \mathrm{bc}$ & $18.16 \pm 0.74 a b$ & $40.0 \pm 10 \mathrm{~b}$ & $15.10 \pm 1.05 \mathrm{a}$ \\
\hline & 2 & $24.0 \pm 1.15 \mathrm{ab}$ & $60.0 \pm 8.82 \mathrm{c}$ & $16.71 \pm 0.91 \mathrm{ab}$ & $40.0 \pm 5.77 b$ & $14.18 \pm 0.84 \mathrm{a}$ \\
\hline & 3 & $33.0 \pm 3.46 \mathrm{c}$ & $30.0 \pm 5.77 \mathrm{~d}$ & $15.06 \pm 0.85 \mathrm{ab}$ & $26.7 \pm 3.33 b$ & $11.14 \pm 0.55 \mathrm{a}$ \\
\hline & 4 & $41.0 \pm 2.65 c$ & $20.0 \pm 5.77 d$ & $14.15 \pm 1.08 \mathrm{~b}$ & $16.7 \pm 3.33 b$ & $11.86 \pm 1.41 \mathrm{a}$ \\
\hline \multirow[t]{4}{*}{0.5} & 1 & $23.50 \pm 0.65 \mathrm{ab}$ & $92.5 \pm 2.5 \mathrm{ab}$ & $17.56 \pm 0.71 \mathrm{ab}$ & $85.51 \pm 5.00 \mathrm{a}$ & $14.61 \pm 0.72 \mathrm{a}$ \\
\hline & 2 & $20.33 \pm 0.58 \mathrm{a}$ & $93.33 \pm 3.3 \mathrm{ab}$ & $16.31 \pm 1.27 \mathrm{ab}$ & $90.0 \pm 5.77 \mathrm{a}$ & $14.60 \pm 0.51 \mathrm{a}$ \\
\hline & 3 & $25.51 \pm 0.96 \mathrm{ab}$ & $77.51 \pm 2.5 \mathrm{abc}$ & $15.41 \pm 0.66 \mathrm{ab}$ & $70.0 \pm 8.16 \mathrm{a}$ & $13.58 \pm 0.51 \mathrm{a}$ \\
\hline & 4 & $30.25 \pm 2.36 b c$ & $75.0 \pm 7.5 \mathrm{c}$ & $14.51 \pm 0.57 \mathrm{~b}$ & $37.51 \pm 9.46 b$ & $12.05 \pm 0.87 \mathrm{a}$ \\
\hline \multirow[t]{5}{*}{0.1} & 3 & $21.75 \pm 0.48 \mathrm{a}$ & $87.54 \pm 4.79 \mathrm{ab}$ & $17.63 \pm 0.58 \mathrm{ab}$ & $82.5 \pm 3.23 \mathrm{a}$ & $14.69 \pm 0.83 a$ \\
\hline & 4 & $22.25 \pm 1.49 \mathrm{a}$ & $95.0 \pm 2.89 \mathrm{a}$ & $16.39 \pm 0.60 \mathrm{ab}$ & $77.53 \pm 7.51 \mathrm{a}$ & $13.45 \pm 0.32 \mathrm{a}$ \\
\hline & $F$ & 18.62 & 30.49 & 2.61 & 18.2 & 2.49 \\
\hline & $d f$ & 10 & 10 & 10 & 10 & 10 \\
\hline & $p$ & $<0.001$ & $<0.001$ & 0.018 & $<0.001$ & 0.014 \\
\hline
\end{tabular}

Values are means of three replicates, each set up with ten larvae $(n=30)$

Means followed by the same letters within each column are not significantly different (one-way ANOVA and Tukey's test, $p<0.05$ )

${ }^{a}$ For structures of the compounds labeled by number in this column, see Fig. 1

$\beta$-damascone-treated larvae were deformed and died soon after emergence. The difference between pupation rate and adult emergence rate was $30.0 \%$ in this treatment, while it was $6.7 \%$ in the controls. This is not surprising, because monoterpenoids very often act as insect growth regulators. Doses of certain essential oils or their components that are too low to kill insects can still induce genotoxic effects and trigger various types of malformations (Halder et al. 2012; Karr and Coats 1988). For example, Argemone mexicana L. (Papaveraceae) extracts reduced adult emergence and increased pupal mortality in S. litura (Malarvannan et al. 2008). Crude extract of Aristolochia elegans Mast. (Aristolochiaceae) produced pronounced deformations and malformations in the larval, pupal, and adult stages of $S$. litura (Arivoli and Tennyson 2013). A high pupal mortality $(35.5 \%)$ was also recorded when lactone 4 was applied at $0.5 \%$ concentration or lactone $2(20 \%)$ was used at a $1 \%$ dose, although they did not cause any malformations. The cause of pupal mortality could be post-ingestion toxicity. The effects of this toxicity could build up over time. After applying the compounds, larvae and pupae died slowly several days after treatment. A post-ingestive toxic effect of polygodial on $S$. littoralis larvae, which did not induce early death, was reported by Zapata et al. (2009).

$\beta$-Damascone was recently discovered to be a potential insecticide against several mosquito species and the housefly (Kaufman et al. 2011). However, neither $\beta$-damascone nor its derivatives showed acute toxicity towards $A$. diaperinus larvae when they were incorporated into the diet at $1 \%$ concentration. Maybe the toxicity of this compound depends on the insect species considered or the method of application. Differences in susceptibility to insecticides/ chemicals among insect species depend primarily upon the diverse biological mechanisms involved in the metabolism of toxic substances. Different species may metabolize or excrete toxic compounds in different ways and at different rates. Sensitivity to $\beta$-damascone even varies among different species of mosquitoes (Kaufman et al. 2011). The main reason for a lack of gastric/dietary toxicity of the $\beta$-damascone derivatives when applied at the maximum dose to food could be their antifeedant activity, which could lead to relatively low doses of the compound being ingested by the larvae. More dead larvae and pupae were observed when the antifeedant activity of the treatment was lower.

In conclusion, our results indicate that $1 \%$ solutions of $\delta$-halolactones with the damascone skeleton are strong antifeedants, and therefore show the potential to be used as an agent for controlling A. diaperinus. These compounds are also very good antifeedants against $A$. diaperinus adults, even at lower doses: 0.5 and $0.1 \%$ (Gliszczyńska et al. 2014). These lower doses are less effective against larvae, with the exception of $\gamma$-bromo- $\delta$-lactone (4), which significantly prolonged larval development as compared to the control larvae when applied at $0.5 \%$ concentration, and its application resulted in both larval and pupal mortality. The adult emergence percentage in this treatment was $37.51 \%$, as compared to $90.0 \%$ in the control larvae. Thus, $\beta$-damascone derivatives with a lactone ring present dosedependent behavioral effects and post-ingestive toxicities 
against A. diaperinus. Moreover, lactone derivatives of $\beta$-damascone were also found to be very active regulators of the behavior of peach-potato aphids, Myzus persicae (Sulz) (Gabryś et al. 2015). They may represent a new group of insecticides that readily biodegrade in the natural environment. The microorganism-catalyzed decomposition of halolactones is based on two main mechanisms: hydrolytic dehalogenation, leading to the substitution of the halogen by a hydroxyl group (Janssen 2004); or elimination of the halogen atom and the formation of a double bond (Grotowska and Wawrzeńczyk 2002; Janssen et al. 2001).

Acknowledgments This project was financed by Nicolaus Copernicus University, grant no. 502-B/2013, and partly by the European Union from the European Regional Development Fund (grant no. POIG.01.03.01-00-158/09-03).

Open Access This article is distributed under the terms of the Creative Commons Attribution 4.0 International License (http://creativecommons.org/licenses/by/4.0/), which permits unrestricted use, distribution, and reproduction in any medium, provided you give appropriate credit to the original author(s) and the source, provide a link to the Creative Commons license, and indicate if changes were made.

\section{References}

Akhtar Y, Isman MB (2004) Comparative growth inhibitory and antifeedant effects of plant extracts and pure allelochemicals on four phytophagus insect species. J Appl Ent 128:32-38

Arivoli S, Tennyson S (2013) Antifeedant activity, developmental indices and morphogenetic variations of plant extracts against Spodoptera litura (Fab) (Lepidoptera: Noctuidae). J Entomol Zool Stud 1:87-96

Baskar K, Kingsley S, Vendan SE, Paulraj MG, Duraipandiyan V, Ignacimuthu S (2009) Antifeedant, larvicidal and pupicidal activities of Atalantia monophylla (L.) Correa against Helicoverpa armigera Hubner (Lepidoptera: Noctuidae). Chemosphere 75:355-359

Bassolé IHN, Juliani HR (2010) Essential oils in combination and their antimicrobial properties. Molecules 17:3989-4006

Bernays EA, Graham M (1988) On the evolution of host specificity in phytophagous arthropods. Ecology 69:886-892

Bouayad N, Rharrabe K, Ghailani NN, Jbilou R, Castañera P, Ortego F (2013) Insecticidal effects of Moroccan plant extracts on development, energy reserves and enzymatic activities of Plodia interpunctella. Span J Agric Res 11:189-198

Chernaki-Leffer AM, Sosa-Gómez DR, Almeida LM, Lopes ION (2011) Susceptibility of Alphitobius diaperinus (Panzer) (Coleoptera, Tenebrionidae) to cypermethrin, dichlorvos and triflumuron in southern Brazil. Rev Bras Entomol 55:125-128

Ćosić J, Vrandečić K, Postić J, Jurković D, Ravlić M (2010) In vitro antifungal activity of essential oils on growth of phytopathogenic fungi. Poljoprivreda 16:25-28

Dancewicz K, Gabryś B, Dams I, Wawrzeńczyk C (2008) Enantiospecific effect of pulegone and pulegone-derived lactones on Myzus persicae (Sulz.) settling and feeding. J Chem Ecol 34:530-538

Demole E, Enggist P, Sauberli U, Stoll M (1970) Structure and synthesis of damascenone [2,6,6-trimethyl-1-trans-crotonyl-1,3-cyclohexadiene], odorous constituent in rose oil (Rosa damascena Mill.). Helv Chim Acta 53:541-551
El-Aswad AF, Abdelgaleil SAM, Nakatani M (2003) Feeding deterrent and growth inhibitory properties of limonoids from Khaya senegalensis against the cotton leafworm Spodoptera littoralis. Pest Manag Sci 60:199-203

Gabryś B, Dancewicz K, Gliszczyńska A, Kordan B, Wawrzeńczyk C (2015) Systemic deterrence of aphid probing and feeding by novel $\beta$-damascone analogues. J Pestic Sci 88(3):507-516

Gliszczyńska A, Dancewicz K, Hnatejko M, Szczepanik M, Gabryś B (2014) Synthesis of $\beta$-damascone derivatives with lactone ring and their feeding deterrent activity against aphids and lesser mealworm. RSC Adv 4:39248-39256

Grotowska A, Wawrzeńczyk C (2002) Lactones 13. Biotransformation of iodolactone. J Mol Catal B Enzym 19-20:203-208

Halder J, Srivastava C, Dhingra S, Dureja P (2012) Effect of essential oils on feeding, survival, growth and development of third instar larvae of Helicoverpa armigera. Natl Acad Sci Lett 35:271-276

Hammer ̌̌, Harper DAT, Ryan PD (2001) PAST: Paleontological Statistics, software package for education and data analysis (online). Palaeontol Electron 4. http://palaeoelectronica.org/2001_1/past/ issue1_01.htm

Hosen M, Khan AR, Hossain M (2004) Growth and development of the lesser mealworm, Alphitobius diaperinus (Panzer) (Coleoptera: Tenebrionidae) on cereal flours. Pak J Biol Sci 7:1505-1508

Isman MB, Brard NL, Nawrot J, Harmatha J (1989) Antifeedant and growth inhibitory effects of bakkenolide-A and other sesquiterpene lactones on the variegated cutworm, Peridroma saucia Hübner (Lep., Noctuidae). J Appl Entomol 107:524-529

Janssen DB (2004) Evolving haloalkane dehalogenases. Curr Opin Chem Biol 8:150-159

Janssen DB, Oppentocht JE, Poelarends GJ (2001) Microbial dehalogenation. Curr Opin Biotechnol 12:254-258

Jeyasankar A, Raja N, Ignacimutu S (2010) Antifeedant and growth inhibitory activities of Syzygium lineare Wall (Myrtaceae) against Spodoptera litura Fab. (Lepidoptera: Noctuidae). Curr Res J Biol Sci 2:173-177

Jeyasankar A, Chennaiyan V, Chinnamani T, Ramaret G (2014) Feeding and growth inhibition activities of Tragia involucrata Linn (Euphorbiaceae) on Achaea janata (Linn.) (Noctuidae: Lepidoptera) and Pericallia ricini (Fab.) (Lepidoptera: Arctiidae). Open Access Libr J 1:e439. doi:10.4236/oalib.1100439

Karr LL, Coats JR (1988) Insecticidal properties of $d$-limonene. J Pestic Sci 13:287-290

Kaufman PE, Mann RS, Butler JF (2011) Insecticidal potency of novel compounds on multiple insect species of medical and veterinary importance. Pest Manag Sci 67:26-35

Koul O (2004) Bioassays in insect antifeedants. CRC, London, pp 25-42

Koul O, Walia S, Dhaliwal GS (2008) Essential oils as green pesticides: potential and constraints. Biopestic Int 4:63-84

Lambkin TA (2001) Investigations into the management of the darkling beetle. Rural Industries Research and Development Corporation, Barton, $\mathrm{p} 1$

Liu F, Liu C, Zeng F (2013) Effects of an artificial diet on development, reproduction and digestive physiology of Chrysopa septempunctata. Biocontrol 58:789-795

Lochyński S, Frąckowiak B, Olejniczak T, Ciunik Z, Wawrzeńczyk C (2002) Lactones. Part 15: synthesis of chiral spirolactones with a carane system-insect feeding deterrents. Tetrahedron Asymmetry 13:1761-1767

Malarvannan S, Giridharan S, Sekar S, Prabavathy VR, Sudha N (2008) Bioefficacy of crude and fractions of Argemone mexicana against tobacco caterpillar, Spodoptera litura Fab. (Noctuidae: Lepidoptera). J Biopestic 1:55-62

Miresmailli S, Isman MB (2014) Botanical insecticides inspired by plant-herbivore chemical interactions. Trends Plant Sci 19:2935. doi:10.1016/j.tplants.2013.10.002 
Nawrot J, Harmatha J (2012) Phytochemical feeding deterrents for stored product insect pests. Phytochem Rev 11:543-566

Pattnaik S, Subramanyam VR, Bapaji M, Kole CR (1997) Antibacterial and antifungal activity of aromatic constituents of essential oils. Microbios 89:39-46

Pavela R (2011) Natural products as allelochemicals in pest management. In: Dubey NK (ed) Natural products in plant pest management. CABI, Wallingford, pp 134-148

Pavela R, Vrchotova N, Šera B (2008) Growth inhibitory effect of extracts from Reynoutria sp. plants against Spodoptera littoralis larvae. Agrociencia 42:573-584

Popławski J, Łozowicka B, Dubis AT, Lachowska B, Winiecki Z, Nawrot J (2000) Feeding-deterrent activity of $\alpha$-asarone isomers against some stored Coleoptera. Pest Manag Sci 56:560-564

Regnault-Roger C, Vincent C, Arnason JT (2012) Essential oils in insect control: low-risk products in a high-stakes world. Annu Rev Entomol 57:405-424

Rharrabe K, Bakrim A, Ghailani N, Sayah F (2007) Bioinsecticidal effect of harmaline on Plodia interpunctella development (Lepidoptera: Pyralidae). Pestic Biochem Physiol 89(2):137-145

Richardson ML, Mitchell RF, Reagel PF, Hanks LM (2010) Causes and consequences of cannibalism in noncarnivorous insects. Annu Rev Entomol 55:39-53

Rodriguez-Saona CR, Trumble JT (1999) Effect of avocadofurans on larval survival, growth, and food preference of the generalist herbivore, Spodoptera exigua. Entomol Exp Appl 90:131-140

Rodriguez-Saona C, Millar JG, Trumble JT (1997) Growth inhibitory, insecticidal, and feeding deterrent effects of $(12 Z, 15 Z)-1$-acetoxy-2-hydroxy-4-oxo-heneicosa-12,15-diene, a compound from avocado fruit, to Spodoptera exigua. J Chem Ecol 23:1819-1831

Rosiński G, Błoszyk E, Harmatha J, Knapik A (1988) Changes produced by sesquiterpenes in some physiological processes in
Tenebrio molitor L. In: Sehnal F, Zabza A, Denlinger DL (eds) Endocrinological frontiers in physiological insect ecology. Wrocław Technical University Press, Wrocław, pp 91-94

Schoonhoven LM (1982) Biological aspects of antifeedants. Entomol Exp Appl 31:57-69

Singh R, Koul O, Rup PJ, Jindal J (2010) Evaluation of dietary toxicity of some essential oil allelochemicals for the management of Chilo partellus (Swinhoe). J Plant Prot Res 50:293-301

Stefanazi N, Stadler T, Ferrero A (2011) Composition and toxic, repellent and feeding deterrent activity of essential oils against the stored-grain pests Tribolium castaneum (Coleoptera: Tenebrionidae) and Sitophilus oryzae (Coleoptera: Curculionidae). Pest Manag Sci 67:639-646

Szczepanik M, Dams I, Wawrzeńczyk C (2008) Terpenoid lactones with $p$-menthane system as feeding deterrents to the lesser mealworm (Alphitobius diaperinus Panzer) (Coleoptera: Tenebrionidae). Entomol Exp Appl 128:337-345

Szczepanik M, Grudniewska A, Zawitowska B, Wawrzeńczyk C (2014) Structure-related antifeedant activity of halolactones with a $p$-menthane system against the lesser mealworm, Alphitobius diaperinus Panzer. Pest Manag Sci 70:953-958

Tignor KR, Eaton JL (1986) Effects of prolonged colonization, crowding, and starvation on development and survival rates of cabbage loopers, Trichoplusia ni (Hübner) (Lepidoptera: Noctuidae). J Entomol Sci 21:68-82

Zapata N, Budia F, Viñuela E, Medina P (2009) Antifeedant and growth inhibitory effects of extracts and drimanes of Drimys winteri stem bark against Spodoptera littoralis (Lep., Noctuidae). Ind Crops Prod 30:119-125 